\title{
CORRELATION OF EXTRA-CURRICULAR ACTIVITIES WITH STUDENTS' STUDY HABITS IN UNIVERSITY OF LAGOS, AKOKA
}

\author{
MARUFF AKINWALE OLADEJO \& MUHIDEEN ADEWALE OLADEJO \\ Dept. of Educational Management, University of Lagos, Nigeria
}

\begin{abstract}
Schools generally are established to expose students to a holistic curriculum that develops them mentally, physically, socially and morally through curricula and extra-curricular activities so as to be properly fit into society and the world of work. Thus, students are expected to par take in one extracurricular activity or the other such as such as music, journalism, debating, sporting, and so on. In the recent times however, it seems there has been low participation of students in these extra-curricular activities. This might not be unconnected with the notion that students' participation in these activities could affect their study time negatively. The present study therefore investigated extra-curricular activities namely music, journalism, debating and sporting as correlates of undergraduate students" study habits in University of Lagos, Akoka. The study used the descriptive research design of the case study type. A self-designed validated and reliable $(r=.86)$ questionnaire was used for data collection. Four null hypotheses formulated and tested of 0.05 level of significance guided the study. A total number of 3500 students was selected through simple random sampling technique. Pearson ProductMoment Correlation Coefficient (PPCC) was used for data analysis. Findings revealed that there was a significant relationship between study habits and students' participation in music $(r=0.398 ; d f$ 3498; $p<0.05)$;journalism ( $r=0.404 ; d f=3498 ; \quad p<0.05)$; debating activities $(r=0.811 ; d f=3498$; $p<0.05)$; and Sporting activities $(r=0.842 ; d f=3498$; $p<0.05)$ respectively. Based on these findings, it was recommended among others, that Institutional administrators should make adequate provisions for necessary equipment and facilities that will encourage students' active participation in extracurricular activities. Healthy competitions among students based on these extra-curricular activities should be encouraged and rewarded accordingly.
\end{abstract}

Keywords: Study habits, Music, Sporting, Debating, Journalism, Extra-curricular

\section{Background to the Study}

Across the world, schools are usually established with a view, among other things, to offering learners a core academic curriculum contents together with other extracurricular activities in order to develop a child to gainful expectations. The former however, is the core reason whose survival is partly influenced by the latter. One aspect of schools that has therefore received increased attention in the literature in the recent times is students' participation in extra-curricular activities. A review of current research substantiates the utility of students' participation in structured extracurricular activities and reveals several benefits of active engagement for middle and high school students (Gilman, Meyers, \& Perez, 2004).

By extra-curricular activities, Larson and Verma (1999) maintained that these are discretionary activities that are physically or mentally stimulating to the individual and contain some structured parameters. They are non-academic programmes, offered during or after school, and within the school premises, or community programmes. While Adeleye (2013) described extra-curricular activities as a set of out-of-class programme or activity, supervised and/or financed by the school, which provides curriculum-related learning and character building experiences, Oladokun (2014) was of the opinion that they are voluntary, not part of the regular school curriculum, not graded and do not earn credits but lead to personality development. Extra-curricular activities therefore refer to other school activities that are offered together with the 
academic curriculum, and which are not though, major components of academic curriculum, an integral part of educational environment. These activities are distinguished from leisure, as extra-curricular activities require effort and a forum to express an identity and passion. They include bands, sports, press club, that is, journalism, literary and debating, acting and drama, music, and cultural activities. This study becomes imperative as it serves as a pointer to whether or not students' engagement in these extra-curricular activities will have anything to do with their study habits.

According to Connell, Halpern-Felsher, Clifford, Crichlow, and Usinger (1995), engaged students reported more positive perceptions of competence, autonomy, and relatedness in the school setting than did students who were less engaged. Furthermore, students (especially high-risk students) involved in school extracurricular programmes were less likely to drop out of school and be involved in delinquent activity (Mahoney, 2000; Mahoney \& Cairns, 1997; Okorodudu, 2000).

These activities are capable of encouraging students to take up their study in a healthy manner so as to be able to form a particular habit. Participating in these activities therefore has been linked to greater school attachment, sense of belonging, better academic achievement, higher academic aspirations, and less risky behaviours such as alcohol and drug use, or dropping out of school (Darling, 2005). Prior to Darling's study, there had been some concerns about students' poor academic performance which was traced to their study habits. For instance, Adeoye (2003) argued that students' involvement in extra-curricular activities without effective time management has been a responsible factor for their bad study habits. Furthermore, contemporary literature argues that participation in co-curricular activities seems to have positive effects on several indicators of academic achievement, namely study habits, academic performance, self-concept and school perception (Marsh, 2002). Oladokun (2014) reported that there was a positive, strong and significant relationship between sporting activity and study habits of the students $[\mathrm{r}(240)=.710$; $\mathrm{df}=$ $238 ; p<.05]$. Thus, these extra-curricular activities seem to have some kinds of relationship with students' study habits.

By study habit, Adeleye (2013) meant "the adopted way and manner a student plans his private readings, after classroom learning so as to attain mastery of the subject". She further argued that "good study habit is a good asset to learners because good habit assists students to attain mastery in areas of specialization and consequent excellent performance, while opposite constitutes constraints to learning and achievement leading to failure" According to Good (1998), study habit refers to student's way of study whether systematic, efficient or inefficient etc". Going by this definition it literally means that good study habit produces positive academic performance while inefficient study habit leads to academic failure. It is against this background that the present study correlated extra-curricular activities namely music, journalism, debating, sporting with students' study habits at the University of Lagos, Akoka.

\section{Statement of the Problem}

Schools should aim for a holistic curriculum that leads to an all-round development of the pupils mentally, physically, socially and morally so that they are properly fit into society and the world of work. Scholars had argued that if students fail to manage 
their time effectively, while being engaged in extra-curricular activities, their study habits might be negatively impacted (Adeleye, 2013; Connell et al., 1995; Oladokun, 2014). However, in the recent contemporary period, it seems there has been low participation of students in extra-curricular activities. Rather, students utilize their precious time on less trivial and non-academic activities. They engage more in social vices such as hooliganism, cultism, smoking, drinking, and betting.

There is the urgent need for a study of this nature in view of the implications it has for the entire education system. For instance, poor students' study habits will lead to poor academic performance, there might be wastages in the education system as a result of drop outs and repletion which can be linked to poor students' study habits.

Several stakeholders in the education industry seem to be of the belief that extracurricular activities consume academic time unnecessarily, while others have pointed to the positive effects of extra-curricular activities on academic success. These inconsistent findings necessitated the need to re-examine the relationship between some of these extra-curricular activities and students' study habits. This study therefore investigated the correlation between extra-curricular activities such as music, journalism, debating, sporting and students' study habits in University of Lagos, Akoka.

\section{Purpose of the Study}

In broad term, the purpose of the study is to investigate the correlation of students' extra-curricular activities with their study habits in University of Lagos, Akoka. Its specific objectives however are:

to determine the relationship between students' participation in music and their study habits in University of Lagos, Akoka.

To examine the extent to which students' participation in journalism and their' study habits in University of Lagos, Akoka are related.

to investigate the relationship between students' participation in sporting activities and their study habits in University of Lagos, Akoka.

to examine the correlation between students' participation in debating activities and their study habits in University of Lagos, Akoka.

\section{Research Hypotheses}

The following null hypotheses were formulated and tested at .05 significant level in this study:

$\mathrm{Ho}_{1}$ : There is no significant relationship between students' participation in music and their study habit in University of Lagos, Akoka.

$\mathrm{Ho}_{2}$ : Students' participation in journalism and their study habits in University of Lagos, Akoka are not significantly related.

$\mathrm{H}_{03}$ : Students' participation in sporting activities does not significantly related to their study habits in University of Lagos, Akoka.

$\mathrm{H}_{04}$ : There is no significant correlation between students' participation in debating activities and their study habits in University of Lagos, Akoka. 


\section{Selected Extra-Curricular Activities and Students' Study Habits}

A brief review of the relationship between each of the selected extra-curricular and students' study habits is carried out in this sub-section. This is done so as to have a much better understanding of the study variables.

As regards music and study habits, Olson (2008) submitted that participation in a school's music programme lessens students' feelings of alienation, promotes individual growth, and provides a common bond between home and school. It can provide adolescents with a social network and a support system that is associated with their school (Darling, Caldwell, \& Smith, 2015).It has been observed that some people cannot study without music, Hills and Ballow (2000) agree that music is good if it does not constitute noise in itself or when used to neutralize other external noise. Studies reflect a strong positive relationship between participation in music and students' study habit (Kelstrom, 1998;Ponter, 1999). Ponter even suggested that "music should be considered as fundamental to the curriculum as Mathematics and Reading", while Kelstrom reported that music instruction actually enhances study habit in areas outside music. In their own contribution, Adewale and Oguntunde (2013) in their study reported a moderate, positive and significant relationship between music and students' study habits. They argued that some students claimed that listening to music or participating in music does not really affect their students.

Journalism activities have also been found to have positive relationship with students' study habits. Studies done by Dvorak (1998) show that high school seniors and college freshman who participated in school newspaper and other journalism activities had higher Grade Point Average (GPA), made fewer errors and scored higher on all measures of information presentation and selection judgment. It can be deduced that the higher GPA obtained might not be unconnected with good study habits formed by the students. In fact, Research has shown that the best predictors of success in the job market are participation incollege media, internships, and appropriate specialization (Becker, Lauf \& Lowrey, 1999). However, another study has found out that playing sports in high school has no significant effect on grades or standardized test scores in the general student population" (Omowale, 2013).

Furthermore, debate participation promotes problem solving and innovative thinking, and helps students to build links between words and ideas that make concepts more meaningful. According to Carroll (2007), many studies show marked improvement in a wide variety of academic skills as a result of participation in competitive debate. This makes debate one of the most successful vehicles for providing affective education to at-risk students. Ultimately, debate increases students' self-confidence by helping to teach them the skills necessary to become competent adults (Bellon, 2000).

Adeoye (2003) declared that the debate process assessed the student's ability to write effectively, work in teams, and analyze arguments, all of which can improve the ability to think critically. Critical thinking that includes debate also allows for collaboration. Nevertheless, some studies regard debate participation as being an extra academic burden, effects on social life, financial costs, and concerns around stress, health consequences and lack of sleep (Oladokun 2014). 


\section{Methodology}

This section presents a description of the procedure adopted in carrying out the present study. This was done under the following sub-headings: research design, population, sample and sampling techniques, instrumentation, validity and reliability of the instrument, and method of data analysis respectively.

\section{Research Design}

The descriptive survey research design of case study type was used in carrying out the study. This was because it enabled the researchers to collect samples from the population in order to examine the distribution, incidence and interaction of educational phenomena in a much deeper manner. Case study type of descriptive design according to Adeleye (2013) is the one in which the investigator will study a single entity, especially an institution in a detailed manner such that findings from such study can be generalised for similar institutions.

\section{Population of the Study}

There are 12 Faculties namely Arts, Basic Medical Sciences, Business Administration, Clinical Sciences, Dental Sciences, Education, Engineering, Environmental Sciences, Law, Pharmacy, Science, and Social Sciences. Also according to the University's Centre for Information and Technology System (CITS), therewere27,826 full time undergraduate students as at 2014/15 academic session excluding foundation students, distance learning students, extra year students, and postgraduate students.

\section{Sample and Sampling Technique}

The Faculty sample size for the study consisted of five randomly selected faculties namely Arts, Basic Medical Sciences, Education, Engineering, and Social Sciences respectively. Also, 3500 undergraduates selected through stratified simple random sampling technique participated in the study. These participants were first stratified into Faculties and then selected randomly.

\section{Research Instrument}

The instrument used for this study was a self-designed validated and reliable questionnaire (r-.86), entitled 'Extra-Curricular Activities and Study Habits Questionnaire (ECASHQ). This was divided into three Sections. Section A provides information about the bio-data of the respondents while second section B comprises five items each on the selected extra-curricular activities namely music, journalism, debating, and sporting. This gives a total of twenty items. Section C measured students' study habits with ten items. Items in Sections B and C are both negatively and positively worded. They were also scored on a four-point modified Likert response options ranging from Strongly Agree (SA), Agree (A), Disagree (D) and Strongly Disagree (SD) with weights 4,3,2, and 1 respectively. All negative items were reverse coded for analysis purpose. 


\section{Validity and Reliability of the Instrument}

In order to validate the instrument, the items of the questionnaire were given to some more experienced Colleagues for necessary corrections. This was done in order to ensure that the instrument measures what it's expected to measure. As regards reliability of the instrument, the researcher used Cronbach method in a pilot study conducted at the Faculty of Science which was not included in the real study. The reliability values for the sub-scales of each of the extra-curricular activities are Music ( $\mathrm{r}=.65)$, Journalism ( $\mathrm{r}=.70)$, Debating $(\mathrm{r}=.77)$ and Sporting $(\mathrm{r}=.64)$ respectively while the overall reliability co-efficient of 0.86 was obtained. This shows that the instrument is reliable.

\section{Method of Data Analysis}

Inferential Statistics, specifically Pearson Product-Moment Correlation Co-efficient (PPCC) was used to test the four formulated hypotheses at 0.05 level of significance.

\section{Findings and Discussions}

In analyzing and interpreting results or the outcome from the data collected, the researcher used the Statistical Package for Social Sciences (SPSS) version 20, using Pearson Product-Moment Correlation Co-efficient.

$\mathrm{H}_{01}$ : There is no significant relationship between students' participation in music and their' study habits in University of Lagos, Akoka.

Table 1: Correlation between Students' Participation in Music and their Study Habits in the University of Lagos, Akoka

\begin{tabular}{llllllll}
\hline Variables & $\overline{\mathrm{X}}$ & $\mathrm{SD}$ & $\mathrm{N}$ & $\mathrm{dfr}$ & $\mathrm{P}$ & Remark & Decision \\
\hline Music & 15.7 & 20.87 & & & & & \\
& 3500 & 34 & 98 & .398 & .001 & Sig. & H0 Reject \\
Study Habits & 10.0 & 10.65 & & & & & \\
\hline
\end{tabular}

Person Product-Moment Correlation Coefficient was used to test the relationship between students' participation in music and their study habits in University of Lagos, Akoka. Table 1 shows that there was a positive, moderate, and significant relationship between students' participation in music and their study habits in University of Lagos, Akoka $(\mathrm{r}=0.398 ; \mathrm{df}=3498 ; \mathrm{p}<0.05)$. Therefore, the null hypothesis which states that there is no significant relationship between students' participation in music and their study habits in University of Lagos, Akoka is rejected.

$\mathrm{HO}_{2}$ : There is no significant relationship between students' participation in journalism and their study habits of undergraduates in University of Lagos, Akoka. 
Table 2: Correlation between Students' Participation in Journalism and their Study Habits in University of Lagos, Akoka

\begin{tabular}{lccccccc}
\hline Variables & $\overline{\mathrm{X}}$ & $\mathrm{SD}$ & $\mathrm{N}$ & $\mathrm{dfr}$ & $\mathrm{P}$ & Remark & Decision \\
\hline Journalism & 13.05 & 0.70 & & & & & \\
& 3500 & 34 & 98 & .404 & .011 & Sig. & H0 Reject \\
\hline Study Habits & 10.01 & 0.65 & & & & &
\end{tabular}

Person Product-Moment Correlation Coefficient was used to test the relationship between students' participation in journalism and their study habits in University of Lagos, Akoka. Table 2 shows that there was a positive, moderate, and significant relationship between students' participation in journalism and their study habits in University of Lagos, Akoka. $(\mathrm{r}=0.404 ; \mathrm{df}=3498 ; \mathrm{p}<0.05)$. Therefore, the null hypothesis which states that there is no significant relationship between students' participation in journalism and their study habits in University of Lagos, Akoka is also rejected.

Ho3: There is no significant relationship between students' participation in sporting activities and their study habits in University of Lagos, Akoka.

Table 3: $\quad$ Correlation Between Students' Participation in Sporting Activities and their Study Habits in University of Lagos, Akoka

\begin{tabular}{lrllllll}
\hline Variables & $\overline{\mathrm{X}}$ & $\mathrm{SD}$ & $\mathrm{N}$ & $\mathrm{dfr}$ & $\mathrm{P}$ & Remark & Decision \\
\hline Sporting & 14.63 & 0.80 & & & & & \\
& 3500 & 34 & 98 & .842 & .021 & Sig. & H0 Reject
\end{tabular}

Study Habits $\quad 10.01 \quad 0.65$

Person Product-Moment Correlation Coefficient was used to test the relationship between students' participation in sporting activities and their study habits in University of Lagos, Akoka. From Table 3, it is shown that there was a positive, strong, and significant relationship between students' participation in sporting activities and their study habits in University of Lagos, Akoka $(r=0.842 ; \mathrm{df}=3498$; $\mathrm{p}<0.05$ ). Therefore, the null hypothesis which states that there is no significant relationship between students' participation in sporting activities and their study habits in University of Lagos, Akoka is rejected.

Ho4: There is no significant relationship between students' participating in debating activities and students' study habits in University of Lagos, Akoka.

Table4: Correlation between Students' Participating in Debating Activities and their Study Habits in University of Lagos, Akoka

\begin{tabular}{lrlccccc}
\hline Variables & $\overline{\mathrm{X}}$ & SD & $\mathrm{N}$ & $\mathrm{dfr}$ & $\mathrm{P}$ & Remark & Decision \\
\hline Debating & 15.65 & 0.82 & & & & & \\
& 3500 & 34 & 98 & .811 .012 & Sig. & H0 Reject \\
\hline
\end{tabular}

Study Habits $10.01 \quad 0.65$

Person Product-Moment Correlation Coefficient was used to test the relationship between students' participation in debating activities and their study habits in University of Lagos, Akoka. Table 4 shows that there was a positive, strong, and significant relationship between students' participation in debating activities and their 
study habits at the University of Lagos, Akoka. ( $\mathrm{r}=0.811$; df $=3498 ; \mathrm{p}<0.05)$. Therefore, the null hypothesis which states that there is no significant relationship between students' participation in debating activities and their study habits in University of Lagos, Akoka also is rejected.

\section{Discussion on Findings}

The study found out that there was a significant relationship between students' participation in music and their study habits in university of Lagos, Akoka ( $\mathrm{r}=0.398$; $\mathrm{df}=3498 ; \mathrm{p}<0.05)$. This is in line with Olson (2008) who opined that participation in a school's music programmelessens students' feelings of alienation, promotes individual growth, and provides a common bond between home and school. In fact, it has been observed that some people cannot study without music. Hills and Ballow (2000) thus, agreed that music is good if it does not constitute noise in itself or when used to neutralize other external noise. Confirming the belief that the relationship between music and study habits is positive, "researchers have found out that music instruction actually enhances study habit in areas outside music" (Kelstrom, 1998). Reason for this finding could be due to the fact that participants in the study are effective in time management. They are able to prioritise their various competing activities such that their study does not suffer.

The study also revealed a significant relationship between students' participation in journalism and their study habits in university of Lagos, Akoka ( $\mathrm{r}=0.404$; $\mathrm{df}=$ 3498;p<0.05). Oladele (2000) reported that students who participated in a journalism activity were ten times as likely to have good study habits, and subsequently choose a journalism/communications major in college and pursue it as a career as other students. Results from the 1997 American Society of Newspaper Editors study found out that $25 \%$ of journalists interviewed decided on their career while they were in high school (Butler, 2006).

As regards the third hypothesis, the present study revealed that there was a significant relationship between students' participation in sporting activities and their study habits in university of Lagos, Akoka $(\mathrm{r}=0.842$; $\mathrm{df}=3498 ; \mathrm{p}<0.05)$. This is line with Stephens and Schaben (2002)who established that the students who participated in more sports for many seasons had a "higher level of scholarship than the students who had competed in only a few seasons or for only one year". However, Eccles (2003)'s study that investigated participation in team sports confirmed that unlike pro-social activities, team sports predicted greater involvement of risky behaviours. Stephens and Schaben performed a study looking at the number of sports each student played and its influence on study habits and academic performance. They noticed that students who participate in at least one sport each year outperformed those who participated in one or less, in class rank, overall GPA, and math GPA. They also noticed that the students who participated in more sports for many seasons had a "higher level of scholarship than the [students] who had competed in only a few seasons or for only one year" (Stephens \& Schaben).

Finally, this study further showed that there was a significant relationship between students' participation in debating activities and their study habits in university of Lagos, Akoka $(\mathrm{r}=0.811 ; \mathrm{df}=3498 ; \mathrm{P}<0.05)$. This finding contradicts finding from the study of Oladokun (2014) which regarded debate participation as being the extra 
academic burden, effects on social life, financial costs, and concerns around stress, health consequences and lack of sleep. Carroll (2007) opined that debate students show more maturity in the face of adversity and tend to develop stronger relationships with peers and mentors than the average student.

\section{Conclusion and Recommendations}

It is important for the school administrators and the school counselors to further recognise the importance of students' involvement in co-curricular activities, because students can benefit from playing games and fitness practices, debate for the development of intellectual capabilities. Some programmes even offer scholarships for participation in extra-curricular activities and leadership development throughout high school. Scholarships may enable students to go on to further their education and open opportunities that they may not have had previously. Therefore, it is important to provide policy makers and administrators with accurate information about the value of co-curricular activities. Based on the findings generated from this study, it is hereby recommended that:

School administrators should sensitize students on the need for them to actively participate in extra-curricular activities and be able to blend them with their academic endeavours. To this end, educational policy makers should come up with policies that will ensure effective implementation of various extra-curricular activities in Nigerian schools.

There should policy formulation that will guarantee adequate provisions of necessary equipment and facilities to promote active participation of students in extra-curricular activities right from basic education level.

Healthy competitions among students based on these extra-curricular activities should be encouraged and rewarded accordingly. 


\section{References}

Adeleye, J.A. (1998). Study habits of university students. World Council of Curriculum and Instruction (WCCI), Region II Forum, 2: 106-114.

Adeoye, R. (2003). Academic and health-related trajectories in adolescence: The intersection of gender and athletics. Journal of Health Education and Social Behavior, 2 (2): 134-205.

Bellon, J. (2000). A research-based justification for debate across the curriculum. Argumentation and Advocacy, 36 (3): 161-176.

Carroll, R. C. (2007, February). Forensics participation as gifted and talented education. Rostrum, 81(6): 31, 34-36.

Darling, N. (2005). Participation in extracurricular activities and adolescent adjustment: Cross-sectional and longitudinal findings. Journal of Youth and Adolescence, 34: 493-505.

Darling, N.; Cadwell, L. L. \& Smith, R. (2015).Participation in school-based extracurricular activities and adolescent adjustment. Journal of Leisure Research, 37: 51-76.

Eccles, J. S. (2003). Extracurricular and other after-school activities for youth. Review of Research in Education, 26: 113-180.

Gilman, R.; Meyers, P. \& Perez, S. (2004). The relationship between life satisfaction, social interest, and frequency of extracurricular activities among adolescent students. Journal of Youth and Adolescence, 30: 749-767.

Hills, Q. \& Barrow, P. (2000). Mental traits as fitness indicators: Expanding evolutionary psychology's adaptationism. In D. LeCroy, \& P. Moller (Eds.), Evolutionary perspectives on human reproductive behavior, 907: 62-74). Annals of the New York Academy of Sciences.

Larson, R. W. \& Walker, K. C. (2010).Dilemmas of practice: Challenges to program quality encountered by youth program leaders. American Journal of Community Psychology, 45: 338-349.

Mahoney, J. L. (2000). School extracurricular activity participation as a moderator in the development of antisocial patterns. Child Development, 71: 502-516.

Mahoney, J. L. \& Cairns, R. B. (1997).Do extracurricular activities protect against early school dropout? Developmental Psychology, 33: 241-253.

Marsh, H. W. (2002). Extracurricular activities: Beneficial extension of the traditional curriculum or subversion of academic goals? Journal of Educational Psychology, 84: 553-562. 
Okorodudu, R. I. (2000). Intelligence and learning. Adolescent Psychology. Delta State University Press, Asaba, Nigeria.

Oladele, M. P. (2000). Fundamentals of Psychological Foundations of Education. Lagos: Loped Publishers Ltd.

Oladokun, P. O. (2014). Toward a psychology of positive youth development. American Psychologist, 55: 170-183.

Stephens, R. \& Schaben, M. (2002). A psychology of human learning. American Psychologist, 55: 111-235. 